the Societies interested in the proposed amalgamation, with a letter from the legal adviser of the Society, was submitted to the Society at a general meeting held on April 5th, 1861, when I was called to order by the President, and so precluded doing what I must now ask the favour of you to allow me to do in your journal-namely, to refer the Fellows to page 363 of vol. iii. of the Proceedings published by the Society, where the scheme will be found fully set out. To that scheme I am prepared to adhere.

Apologising for intruding myself on your space,

May, 1869. I am, Sir, yours \&c., Charles Hawtins.

\section{THE MEDICAL PROFESSION AND INSURANCE OFFICES.}

To the Editor of Tre Lancer.

SIR,-It may interest the profession to know that, during the past week, I have succeeded in obtaining a fee from an insurance office, by inquiring if there was any objection to my sending a short correspondence on the subject to THE LANCET. I had received a "Private Friend's" form, and on writing to ask if I was to be paid for my reply, received the usual answer, that it was not in a professional capacity I was applied to, but as a private friend; and that if I objected to reply in that capacity, the manager would have to apply to the proposer for the name of another friend.

In reply, I sent an extract from The Lancot of April 3rd, containing your remarks on Dr. Day's case, and said I presumed there would be no objection to my sending our correspondence to THE LANCET.

The manager replied that he did altogether object to this being done, and enclosed a medical form, upon filling up which the fee would, he said, be sent. The form was fllled up; and by return of post I received a P.O. order for one guinea. $\quad \mathrm{I}$ am, Sir, your obedient servant,

Fitzroy-square, April 26th, 1869.

$$
\text { H. Nelson Hardy, M.R.C.S. }
$$

\section{PLURALTTY OF APPOINTMENTS. To the Editor of The LanceT.}

SIR,-The following statement may excite inquiry in these days of hospital abuse and plurality of appointments.

Dr. Grindley Pearse, a vaccinator and teacher of vaccination at the Tottenham-court-road Station, and at IVarshamstreet, Westminster (vide list from the Privy Council Office), has just been appointed by the guardians sole Public Vaccinator in the Westminster District, which comprises the parishes of St. Margaret and St. John, containing a population of 68,000 souls. Is this fair to the late vaccinators? I am, Sir, yours faithfully, Justitia.

\section{TREATMENT OF BELLADONNA-POISONING BY OPIUM.}

To the Editor of TeE LANCET.

SIR,-With reference to the case of morphia-poisoning reported in your journal of the 3rd inst., in which atropia was injected hypodermically with suceess, the following case may prove interesting as to some extent evidencing the power these drugs have in counteracting the effects of each other.

On the morning of the 1st inst., at about half-past five o'clock, I was called to see a patient who had, four hours and a half previous to my arrival, taken six grains of extract of belladonna, which had been given him in mistake for colocyuth. On my arrival, the patient informed me that he took the medicine as an intended aperient on going to bed. He awoke after two hours' sleep, felt very restless, continually getting out of bed to moisten with water his mouth and throat, which had become much parched. He felt giddy, and his sight was so dim that small objects could not be seen. His urine was suppressed, and he experienced a sensation as of sinking through the floor. The patient had a wild and anxious look, and a difficulty in utterance. The pupils were much dilated; tongue dry and furred; pulse slow and labouring. He was quite conscious, free from pain, and his breathing was undisturbed. As the poison had been taken too long to expect benefit from an emetic, or the use of the stomach-pump, I ordered him to make free use of stimulants, and-to prevent his sleeping-to be kept constantly on the move.

About an hour after I left the patient, I was informed by his wife that he was much worse; he had been seized with spasms in the legs, similar-as he described it-to electric shocks passing from the trunk to the extremities, and lifting them from off the ground. He was unable to walk, and had become so drowsy that his wife found it impossible to keep him awake. I ordered him thirty minims of tincture of opium, in an ounce of camphor-water, which, in his own language, had almost an immediate beneficial effect. "The whole of the symptoms commenced to improve, and the same dose repeated within a few hours left me quite free from any unpleasant effects, with the exception of a peculiar sensation in the mouth, lips, and hands, which remained. for some days."

I am, Six, your obedient servant,

Finsbury-place, April 5th, 1869. G. BonLASE CHILDS, F.R.C.S.

\section{SHEFFIELD.}

(FROM OUR OWN CORRESPONDENT.)

A Lectureship on Anatomy at the Sheffield School of Medicine has become vacant by the death of Mr. Skinner. For nearly twenty years he occupied the chair, and though engaged largely in public and private practice, the occasions on which he was absent from his place in the theatre, at the appointed hour, may be counted on the fingers. Always in the habit of attending half an hour before the time, and preparing, or seeing prepared, the dissection for the day, he delivered lectures remarkable for graphic force and precision. Gentlemen who attended his lectures, and afterwards those of the great masters in London and Dublin, have assured the writer that for clearness in demonstration he was unequalled.

The whole construction and ventilation of the fine General Infirmary here, are perhaps as faulty as in any building of the kind in Great Britain. The staff have lodged a formal protest upon the subject with the Governing Board, and it is hoped that this, together with the example of Leeds and of the neighbouring town of Rotherham, which is erecting a dispensary and hospital on the best principles of construction, will relieve Sheffield of the opprobrium of an hospital worthy of those days when, in the Hôtel Dieu, three patients occupied one bed half of the twenty-four hours, giving place, at the end of that time, to three others who had been patiently waiting their turn in the thalamus of death on an adjoining bench.

The medical clinique at the Infirmary is, as usual, rich in paradigm cases. Under one of the physicians there are now :- -

1. A case of Hodokin's disease, sarcoma lymphaticum of the spleen, which has been under observation for three years. Three times the patient has presented himself with universal anasarca, internal hæmorrhage, and an almost incredible degree of anæmia. Three times he has improved under iron and lemon-juice, so far as to be able to resume his place at the forge. Curiously enough, too, an axillary adenopathy, which appeared twelve months ago, has disappeared. The spleen still remains enlarged.

2. A case of atrophie musculaire progressive, in a very early stage, to which the attention of the physician was called only by the dilatation of the pupils, and the presence of a severe neuralgia of the greater occipital. The wasting is confined to the upper extremities, and his oceupation-a puddler-gives the clue to the etiology of the disease. The application of the continuous current has been prescribed.

3. A case of vitiligoidea plana et tuberosa.

4. By the side of the case of Cruveilhier's disease, two cases of lead poisoning, with palsy and wasting; and a case of ataxy, which has improved to an unexpected degree under phosphorus. 